\title{
FUN LEARNING FOR KIDS: STIMULASI PENGENALAN BUAH- BUAHAN PADA SISWA TAMAN KANAK-KANAK ISLAM DI JAKARTA
}

\author{
Erlina Wijayanti $^{1 *}$, Dini Widianti ${ }^{1}$, Citra Dewi ${ }^{1}$ \\ ${ }^{1}$ Bagian Ilmu Kesehatan Masyarakat, Fakultas Kedokteran Universitas YARSI, Jakarta, Indonesia \\ *Penulis Korespondensi: erlina.wijayanti@yarsi.ac.id
}

\begin{abstract}
Abstrak
Dalam membiasakan mengkonsumsi buah, perlu menggunakan teknik yang yang melibatkan aspek kognitif, verbal serta motorik akan lebih mudah diterima oleh anak-anak, terlebih jika teknik yang digunakan juga menyenangkan. Tujuan kegiatan adalah menyampaikan pengetahuan tentang buahbuahan pada anak. Sasaran kegiatan adalah guru dan siswa di Raudatul Athfal (RA) Asy-Syuhada, Serdang, Jakarta Pusat. Metode kegiatan yang digunakan berupa pelatihan untuk guru dilanjutkan dengan pembelajaran bagi siswa menggunakan metode story telling, bernyanyi, permainan "Lihat Lebih Dekat" serta kolase dan mewarnai gambar buah. Guru yang terlibat sebayak 3 orang sedangkan siswa yang terlibat adalah siswa TK B sebanyak 54 orang. Pada akhir kegiatan, pengetahuan siswa baik sebanyak 47 siswa (87\%), cukup 6 siswa (11\%) dan kurang 1 siswa (2\%). Diharapkan pengabdian masyarakat ini dapat meningkatkan rasa suka anak terhadap konsumsi buah dan dapat memberdayakan guru agar kreatif mengenalkan buah pada anak. Diharapkan juga metode yang dikenalkan dapat memberikan kontribusi bagi penyelesaian masalah konsumsi buah pada anak.
\end{abstract}

Kata kunci: fun learning, pengenalan buah-buahan, siswa taman kanak-kanak, RA

\begin{abstract}
To build the children's habit of consuming fruit, it is necessary to use techniques that involve cognitive, verbal and motor aspects, especially a fun learning. The purpose of the project is to convey knowledge about the fruit in the child. The activity targets are teachers and students in RA Asy-Syuhada at Serdang in the Central Jakarta. The methods that used are training for teachers followed by learning for the students using the story telling, singing, game "Closer with Fruit", collage and coloring pictures of fruit. Teachers are involved as 3 people while the students involved are TK B students as much as 54 children. At the end of the activity, the students' knowledge is good as many as 47 students (87\%), moderate as many as 6 students (11\%) and less about 1 student (2\%). It is expected that students will frequently eat fruits and the activity can empower teachers to creatively introduce fruit to children. It is also hoped that the methods can contribute to solving the problem of fruit consumption in children.
\end{abstract}

Keywords: fun learning, fruits, kindergarten student, $R A$

\section{PENDAHULUAN}

Pola makan masyarakat Indonesia telah mengalami pergeseran sejak tahun 1980. Masyarakat lebih banyak mengkonsumsi makanan instan dan rendah serat (Badan Penelitian dan Pengembangan Kesehatan Kemenkes RI, 2013). Hal ini memiliki risiko terhadap terjadinya penyakit tidak menular seperti kanker, hipertensi, sindrom metabolik dan sebagainya (Arisman, 2010).

Serat merupakan sumber zat pangan yang banyak bermanfaat antara lain mengurangi kadar gula darah, mencegah kanker, dan mencegah obesitas. Pembiasaan konsumsi serat alami merupakan gerakan yang sudah dicanangkan WHO sejak 30 tahun yang lalu. Salah satu sumber serat alami adalah buah. Selain serat, buah mengandung vitamin dan mineral yang diperlukan oleh tubuh untuk mendukung proses metabolism (Almatsier, 2004).

Anjuran back to nature oleh WHO tidak hanya diperuntukkan bagi orang dewasa akan tetapi juga anak-anak. Pembiasaan yang diawali sejak usia dini akan mempermudah penerapan pola hidup sehat saat dewasa nanti. Dalam membiasakan mengkonsumsi buah, perlu menggunakan teknik yang 'ramah anak'. Pembelajaran yang melibatkan aspek kognitif, verbal serta motorik akan lebih mudah diterima oleh anakanak, terlebih jika teknik yang digunakan juga menyenangkan (Rifanto, 2010).

RA Asy-Syuhada berlokasi di Jl. Taruna RT 019/03 no 3A Serdang Jakarta Pusat. RA ini memiliki 104 siswa yang terdiri dari play group, TK A dan TK B. Kurikulum pengenalan buah ke siswa masih belum 
terintegrasi dalam materi pembelajaran. Berdasarkan hasil wawancara dengan orang tua siswa, ditemukan beraneka masalah dalam membiasakan makan buah pada anak antara lain anak tidak suka makan buah bahkan cenderung mual bila melihat buah atau anak menolak makan buah dan memilih makan snack dan jajanan kurang sehat.

Usia dini (terutama 3-5 tahun) adalah periode anak mulai aktif memilih makanan (Barness \& John, 2000).

Oleh karena itu anak perlu stimulasi (dorongan/rangsangan) supaya muncul rasa senang mengkonsumsi buah terutama buah-buahan yang mudah didapat dan sering ditemui sehari-hari seperti buah-buahan tropis (buah durian, rambutan, belimbing, dan lain-lain).

RA Asy-Syuhada merupakan sekolah yang menjadi sasaran kegiatan pengabdian masyarakat yang diselenggarakan oleh Universitas YARSI pada Maret 2017 lalu. Kegiatan pengabdian masyarakat yang telah dilakukan adalah pelatihan kader gizi untuk mengenalkan buah dan sayur pada anak.

Kegiatan pengabdian masyarakat yang akan dilakukan merupakan lanjutan dari kegiatan pelatihan kader gizi tersebut diatas dan akan fokus pada kegiatan pembelajaran yang menyenangkan "Fun learning for Kids: Stimulasi Mengenalkan Buah pada Anak" (Wijayanti, dkk, 2017). Sasaran kegiatan adalah guru/kader gizi dan siswa.

\section{BAHAN DAN METODE}

Metode kegiatan yang digunakan berupa pembelajaran dengan menggunakan metode berikut.

a. "Story telling"

Kisah yang disampaikan kepada anak-anak berjudul "Zahra Suka Buah" yang berisikan tentang ajakan mengkonsumsi buah. Cerita ini disampaikan dengan menggunakan boneka tangan.

b. Bernyanyi "Tebak Buah" dan "Buah Pepaya"

Anak-anak diajak bernyanyi agar bersemangat dan fokus pada materi yang disampaikan. Selain itu juga bertujuan menambah pengetahuan tentang buah durian, rambutan dan papaya.

c. "Lihat Lebih Dekat"

Permainan ini menggunakan beberapa macam buah. Siswa melihat dengan cermat bentuk, warna, tekstur dan mencicipi rasanya. Buah yang dikenalkan adalah buah naga, belimbing dan apel.

d. Kolase buah dan mewarnai

Siswa menempel kertas berwarna dan mewarnai gambar buah-buahan. Tujuan yang ingin dicapai untuk melatih motorik halus siswa dan mengenalkan bentuk serta warna buah.

\section{HASIL DAN PEMBAHASAN}

Kegiatan diselenggarakan pada hari Rabu, 24 Januari 2018 dan diikuti oleh 3 guru TK yang ikut serta memberikan pengenalan buah pada anak. Siswa yang terlibat sebanyak 54 siswa.

Kegiatan diawali dengan briefing guru. Kegiatan ini bertujuan untuk memberikan gambaran kegiatan sekaligus melibatkan guru pada saat pelaksanaan. Harapannya guru dapat melakukan kegiatan secara mandiri dan berkelanjutan.

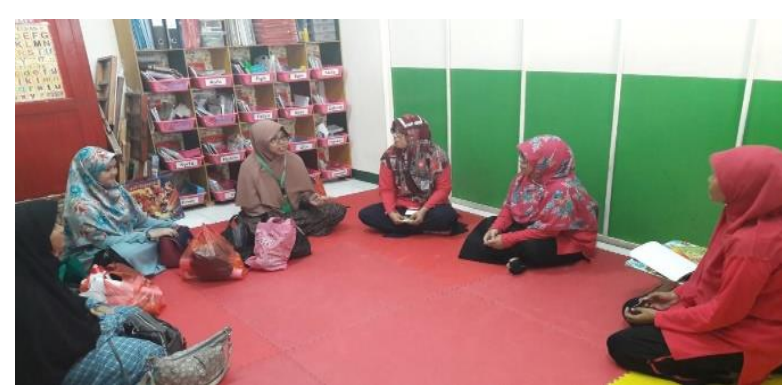

Gambar 1. Briefing tim pengabdian masyarakat dengan guru RA Asy-Syuhada

Kegiatan selanjutnya adalah mempersiapakan siswa agar bersemangat dan dapat beradaptasi dengan anggota tim yang akan memberikan materi pengenalan buah.

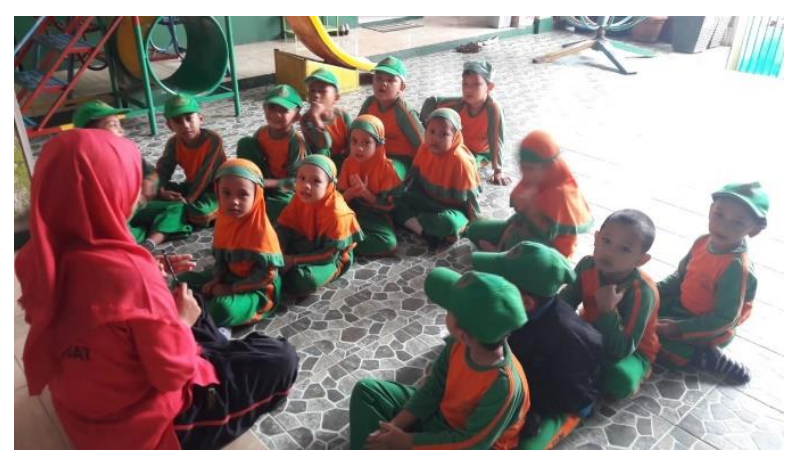

Gambar 2. Persiapan siswa sebelum mengikuti kegiatan Fun Learning Mengenal Buah

Acara inti diawali dengan bernyanyi. Lagu yang dinyanyikan berjudul "Tebak Buah Apa" dan "Buah Pepaya". Tujuan dari bernyanyi ini agar anak-anak bersemangat, fokus dan mencairkan suasana. Selain itu juga di dalam syair lagu memperkenalkan mengenai bentuk buah durian dan rambutan serta mengenalkan manfaat buah pepaya.

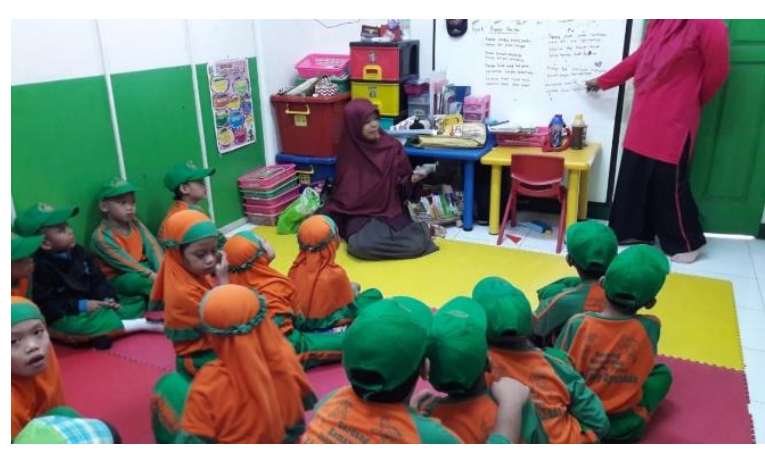

Gambar 3. Bernyanyi lagu "Tebak Buah Apa" dan "Buah Pepaya" 
Story telling menggunakan boneka tangan agar lebih menarik dan memudahkan anak-anak berimajinasi dengan cerita yang disampaikan yaitu Zahra Suka Buah. Cerita ini berkisah tentang seorang anak yang senang memakan buah dan mengajak teman-temannya untuk memetik dan mencicipi buah. Teman-teman Zahra pun menyukai buah-buahan dan ingin lebih sering memakannya setiap hari.

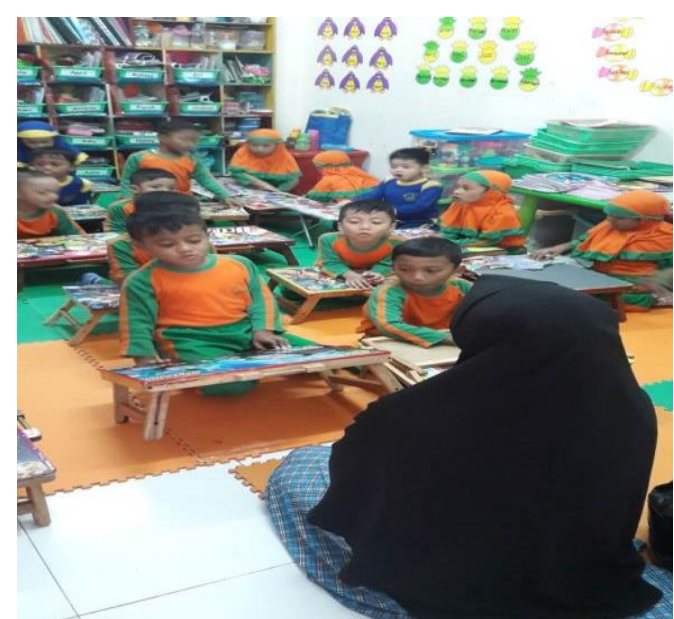

Gambar 4. Story Telling tentang cerita Zahra Suka Buah

Kegiatan inti berikutnya adalah melihat buah-buah dari fisik luar kemudian tekstur nya serta mencicipi rasa. Buah-buahan yang diperkenalkan di sesi ini adalah buah naga, belimbing dan apel.

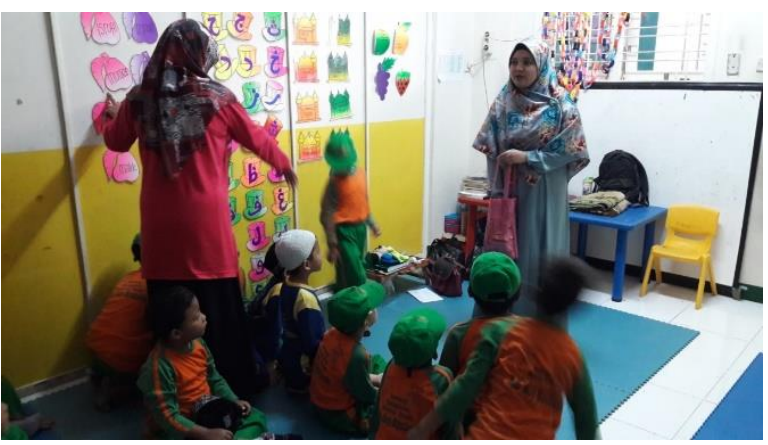

Gambar 5. Bermain "Lihat Lebih Dekat" dengan buah naga, belimbing dan apel

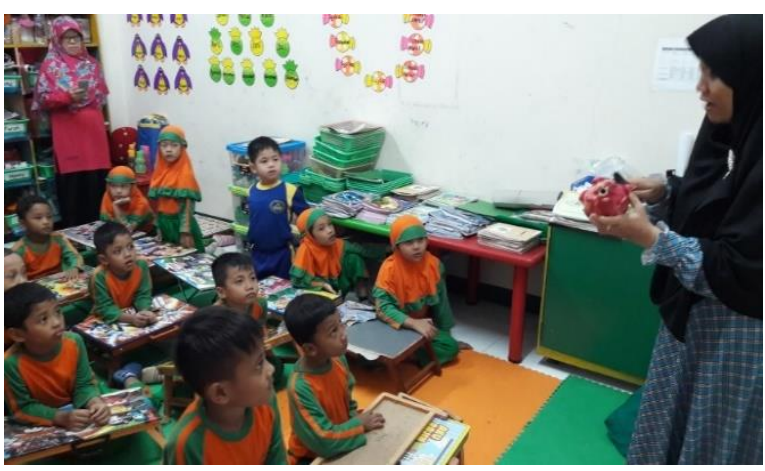

Gambar 6."Lihat Lebih Dekat” buah naga (1)

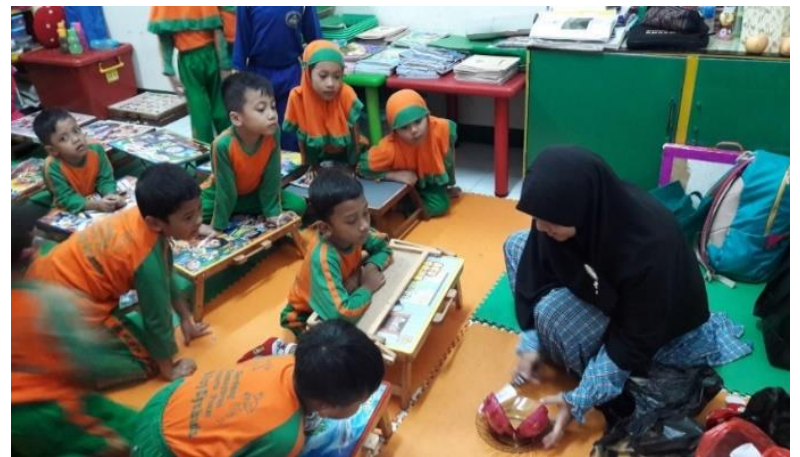

Gambar 7. "Lihat Lebih Dekat"buah naga (2)

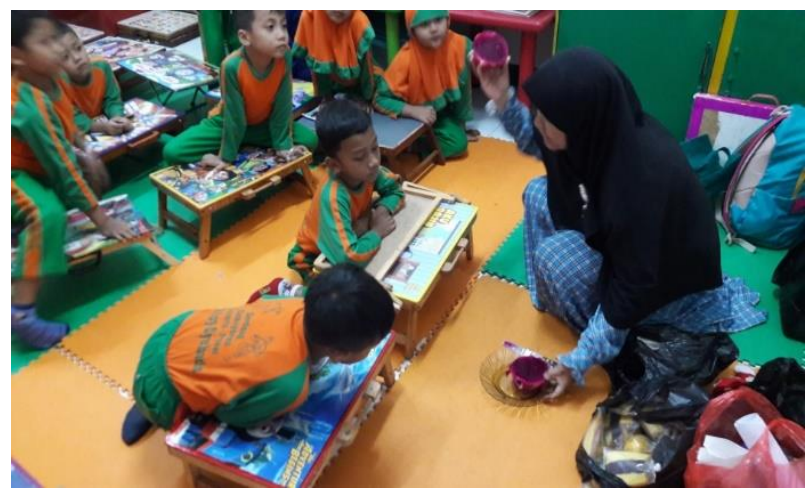

Gambar 8. "Lihat Lebih Dekat" buah naga (3)

Selanjutnya motorik halus anak, kemampuan seni dan imajinasi mereka dilibatkan dalam sesi membuat kolase buah dan mewarnai. Tim pengabdian masyarakat sudah mempersiapakan gambar buahbuahan untuk ditempeli kertas berwarna dan diwarnai.

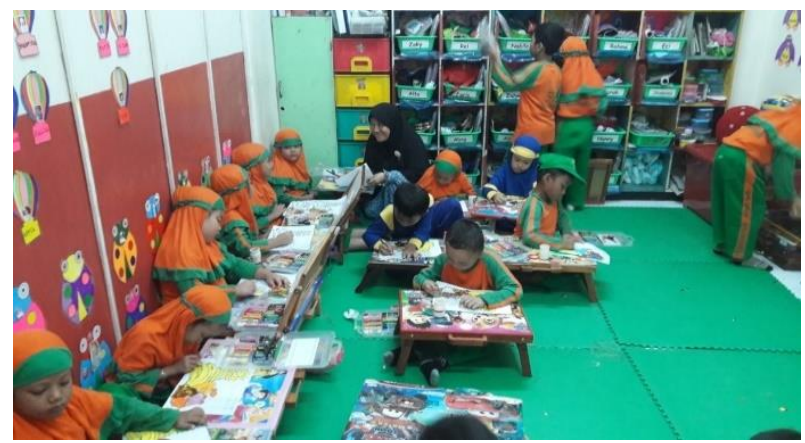

Gambar 9. Kegiatan kolase buah

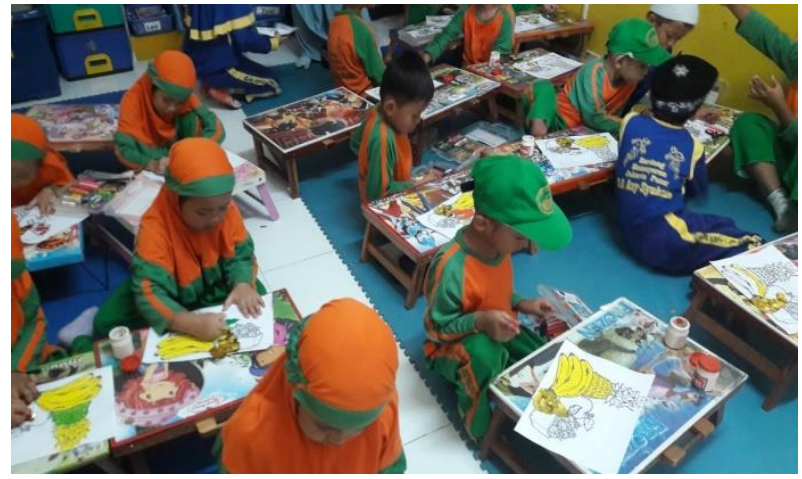

Gambar 10. Mewarnai gambar buah 


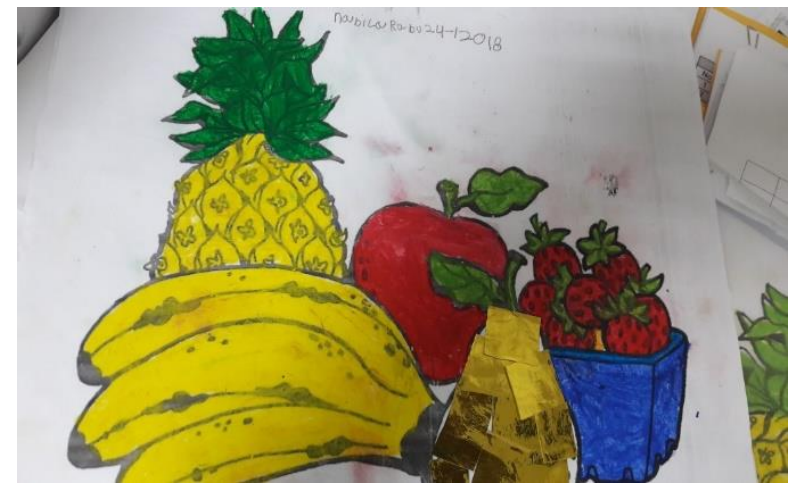

Gambar 11. Hasil kolase dan mewarnai salah seorang siswa

Sebelum ditutup dilakukan evaluasi kegiatan dengan mengukur pengetahuan siswa. Berikut ini pengetahuan siswa setelah kegiatan.

Tabel 1. Gambaran pengetahuan peserta setelah kegiatan pengabdian masyarakat

\begin{tabular}{lcc}
\hline \multicolumn{1}{c}{$\begin{array}{c}\text { Tingkat } \\
\text { pengetahuan }\end{array}$} & Jumlah & Persentase \\
\hline Baik & 47 & $87 \%$ \\
Cukup & 6 & $11 \%$ \\
Kurang & 1 & $2 \%$ \\
Total & 54 & $100 \%$ \\
\hline
\end{tabular}

Dari tabel 1 terlihat bahwa mayoritas siswa memiliki pengetahuan baik. Hal ini salah satunya ditunjang dari teknik penyampaian yang dapat dimengerti oleh anak. sebagaimana teori komunikasi persuasi oleh Schwerin dan Newell (1981) dalam Kholid (2014) yang menyatakan bahwa media dan daya tarik pesan menjadi penentu keberhasilan promosi kesehatan selain faktor komunikator dan komunikan.

\section{KESIMPULAN}

Kegiatan Fun Learning For Kids sudah dilakukan di RA Asy-Syuhada dengan melibatkan 3 guru sebagai asisten pemateri dan 54 siswa sebagai peserta. Rangkaian kegiatan berupa story telling, bernyayi, melihat buah lebih dekat dan kolase serta mewarnai buah. Pada akhir kegiatan, pengetahuan siswa baik sebanyak 47 siswa (87\%), cukup 6 siswa (11\%) dan kurang 1 siswa (2\%). Artinya kegiatan ini memberikan dampak positif terutama bagi siswa. Pihak sekolah dan guru juga mendapat manfaat yaitu mengetahui urgensi mengenalkan buah pada siswa dan teknik stimulasinya. Kegiatan ini diharapkan dapat memberikan kontribusi bagi penyelesaian masalah konsumsi buah pada anak dan menjadi bahan masukan bagi kegiatan pengabdian masyarakat selanjutnya.

\section{UCAPAN TERIMAKASIH}

Ucapan terimakasih diberikan kepada Universitas YARSI yang telah membiayai jalannya kegiatan pengabdian masyarakat ini.

\section{DAFTAR PUSTAKA}

Almatsier, S. (2004). Prinsip Dasar Ilmu Gizi. PT.Gramedia Utama: Jakarta

Arisman. (2010). Gizi Dalam Daur Kehidupan. Penerbit Buku Kedokteran EGC: Jakarta.

Badan Penelitian dan Pengembangan Kesehatan Kemenkes RI. (2013). Riset Kesehatan Dasar. Jakarta

Barness, L.A., \& John, S.C. (2000). Nutrisi: ilmu kesehatan anak Nelson Vol. 1 (terjemahan). Penerbit Buku Kedokteran EGC: Jakarta.

Kholid, A. (2014). Promosi Kesehatan. Rajawali Pers: Jakarta

Rifanto, R. (2010). Quantum Learning at Home: 3 Menit Membuat Anak Keranjingan belajar. Gramedia: Jakarta

Wijayanti, E., dkk. (2017). Modul Fun Learning For Kids: Mengenalkan Buah dan Sayur untuk Anak Usia Dini. Bagian IKM Universitas YARSI: Jakarta 